\title{
[22 23]分子量分布之溶液物性
}

第 1 報 沈降および拡散測定によって得られる分子量の平均值

(1960 年 9 月 1 日受理)

山田信夫* ・松田英臣*

要 旨沈降抢よび拡散の測定から, Svedverg の関係式を使って求めた高分子の分子量 $\bar{M}_{S D}$ の平 均の性質は，次のように書けることがわかった。

$$
\bar{M}_{S D}=\frac{\sum_{i} w_{i} M_{i}^{1-\gamma}}{\sum_{i} w_{i} M_{i}^{-\gamma}}
$$

ここに, $\gamma$ は, 分子量と拡散定数との間の関倸式 $D=K_{I I I} M^{-\gamma}$ によって与えられるものである。また, $\bar{M}_{S D}$ と, 重量平均分子量 $\bar{M}_{w}$, 数平均分子量 $\bar{M}_{n}$ の間に注次の関保がある。

$$
\bar{M}_{S D}=\bar{M}_{w}-\gamma\left(\bar{M}_{w}-\bar{M}_{n}\right)
$$

\section{1. 緒言}

通常, 沈降速度法によって高分子物質の分子量 $\bar{M}_{S D}$ を求めるときは, 超遠心機による沈降定数 $S_{0}$ の測定と, 拡散による拡散定数 $D_{0}$ の測定とを組み合わせて, Svedverg の式を用いて分子量を計算せねばならない。 この場合，沈降定数は，沈降曲線の極大位置の時閒的変 化より，また，㹡散定数は拡散曲線の能率から計算する のが普通である。分子量に多分散性をもつ通常の高分子 溶液においては, 拡散曲線の何次の能率から計算したか によって異なった平均量の拡散定数を与える1”。れゆ え,このようにして求めた分子量は, 用いた拡散定数の 種類によって異なってくるばかりでなく，その平均の性 質もまた不明である。そのために，たとえば光散乱測定 で得られる重量平均分子量や，浸透圧測定で得られる数 平均分子量などと比較して議論をすすめることもできな いし，また,なんらかの手段で, 分子量分布曲線が得られ ている場合でも，実測された分子量に $\bar{M}_{S D}$ 対応する分 子量をその分布曲線から計算することもできない。も ちろん,このことに関して考察を加えた論文はないわけ ではないが，ほとんど具体的記述にかけていると思われ るものが多(2),8) それゆえ,この論文においては, 沈降 速度法によって得られる分子量 $\bar{M}_{S D}$ の平均の性質を明 らかにし, 重量平均分子量 $\bar{M}_{w}$ や数平均分子量 $\bar{M}_{n}$, と どのような関倸にあるかを考察することを目的とした。

\section{2. 分子量 $M_{\mathrm{S} D}$ の平均の性質}

沈降定数 $S_{0}$ と, 拡散定数 $D_{0}$ とから分子量 $\bar{M}_{S D}$ を求 めるには, Svedverg の関係式が用いられる。

$$
\bar{M}_{S D}=\frac{R T S_{0}}{D_{0}(1-\bar{v} \rho)}
$$

\footnotetext{
* 電気通信研究所 (武蔵野市吉祥寺 1551)
}

ここに, $\rho$ は溶媒の比重, $\bar{v}$ は溶質の部分比容, $T$ 絶対 温度， $R$ は気体定数である。緒言において述べたように このようにして求めた $\bar{M}_{S D}$ は，その平均の性質が不明 である。これを明らかにするためには，(1)式に用いた沈 降定数, および拡散定数の平均の性質が明らかにされね ばならない。

細野，桜田によれば，分子量分布をもつ高分子物質の 拡散において, 拡散曲線の $2 n$ 次の能率から計算される 拡散定数 ${ }_{n} D_{m i x}$ の $n$ 乗は, 拡散定数の重量分布関数の $n$ 次の能率に等しいことが知られている゙)。

$$
{ }_{n} D^{n}{ }_{m i x}=\frac{\sum_{i} w_{i} D_{i}{ }^{n}}{\sum_{i} w_{i}} \quad n \geq 1
$$

ここに $w_{i}$ は $D_{i}$ なる拡散定数を持つ分布のない試料の 重さである。また， ${ }_{n} D^{n}{ }_{m i x}$ は，通常の拡散実験加容易 に得ることができる。そこで，一般に， $n$ 次の拡散定数 は次のように定義できる。

$$
{ }_{n} D_{\text {mix }}=\left(\frac{\sum_{i} w_{i} D_{i}^{n}}{\sum_{i} w_{i}}\right)^{\frac{1}{n}} \quad n \geq 1
$$

特に $n=1$ の場合は, (3) 式は拡散定数の重量平均値を与 える。そしてこれは, われわれの拡散実験でモーメント 法で測定された拡散定数 $D_{m}$ に対応する ${ }^{1)}$ 。

(3)式と対応させて, われわれは $n$ 次の沈降定数を次 のように定義できる。

$$
{ }_{n} S_{m i x}=\left(\frac{\sum_{i} w_{i} S_{i}^{n}}{\sum_{i} w_{i}}\right)^{\frac{1}{n}} \quad n \geq 1
$$

$w_{i}$ は $S_{i}$ なる沈降定数をもつ試料の重さである。(4)式 は, 沈降定数の重量分布曲線がわかっていれば計算する ことができる。拡散定数の場合と同様に， $n=1$ の場合 
は，(4)式は沈降定数の重量平均值を与える。沈降定数の 重量分布曲線は, 沈降実験で得られる沈降曲線から容易 に求めることができるが,8)。しかむ，普通に得られてい る沈降定数 $S_{0}$ は，(4)式において $n=1$ とした場合の镇、 すなわち, 沈降定数の重量平均値とほとんど一致するこ とが実験的に知られている゙)。それゆえ，(3)，(4)式のご とき平均のわかった搪散定数扰よび沈降定数を使えば， $\bar{M}_{S D}$ の平均を計算し，しかも実験と比較することが可 能となる。

今, (3), (4)式を(1)式に代入すれば次式を得る。

${ }_{n} \vec{M}_{S D}=\left[\frac{R T}{(1-\bar{v} \rho)}\right]\left(\frac{\sum_{i} w_{i} S_{i}^{n}}{\sum_{i} w_{i}}\right)^{\frac{1}{n}} /\left(\frac{\sum_{i} w_{i} D_{i}^{n}}{\sum_{i} w_{i}}\right)^{\frac{2}{n}}$

沈降定数および拡散定数と分子量との関倸を与える Simhaによって提出された式》が，一般に分子量分布の ない系に対しても成立すると仮定する。

$$
\begin{aligned}
& S_{i}=K_{I I} M_{i}^{i-\gamma} \\
& D_{i}=K_{I I I} M_{i}^{-\gamma}
\end{aligned}
$$

ここに $S_{i}$ および $D_{i}$ は, 分子量 $M_{i}$ なる試料の沈降定数 および拡散定数である。また， $K_{I I}, K_{I I I}, \gamma$ は，高分子と 溶媒の種類拉よび温度によって決定される定数である。 (6)式を使えば(5)式はつぎのように書くことができる。

$$
{ }_{n} \vec{M}_{S D}=\left[\frac{R T K}{(1-\bar{v} \rho)}\right]\left[\frac{\sum_{i} w_{i} M_{i}^{n(1-\gamma)}}{\sum_{i} w_{i} M_{i}^{-n_{\gamma}}}\right]^{\frac{2}{n}}
$$

ただし， $K=K_{I I} / K_{I I I}$ である。

沈降定数 $S_{0}$, 㹡散定数 $D_{0}$ は, よく知られているつぎ の関係がある。

$$
\left.\begin{array}{l}
S_{0}=\frac{M(1-\hat{v} \rho)}{f} \\
D_{0}=\frac{R T}{f}
\end{array}\right\}
$$

ここに $f$ は溶質と溶媒の摩擦俰数である。(6), (8) 式を 使らと, (7)式の最初の! ] の定数項は 1 となる。

$$
\frac{R T K}{(1-\bar{v} \rho)}=1
$$

それゆえに，沈降速度法で得られる分子量の平均は，つ ぎのように書くことができる。

$$
{ }_{n} \bar{M}_{S D}=\left[\frac{\sum_{i} w_{i} M_{i}^{n(1-\gamma)}}{\sum_{i} w_{i} M_{i}^{-n_{\gamma}}}\right]^{\frac{1}{n}} n \geq 1
$$

(10)式を䇢算するにあたって，原理的には次数の異なっ た沈降定数と拡散定数を使らことは可能であるが，それ は平均値の性罂をいたずらに混乱させるばかりであるの
で，通常は同じ次数の $S_{0}$ と $D_{0}$ を使うことが望をしい。 また, 前にも述べたように, 通常の沈降実験で求めた $S_{0}$ および，モーメント法で求めた $D_{m}$ は， $n=1$ の場合 の値にそれぞれ対応するので, (10)式もつぎのように簡 単に畫ける。

$$
\bar{M}_{S D}=\frac{\sum_{i} w_{i} M_{i}^{1-\gamma}}{\sum_{i} w_{i} M_{i}^{-\gamma}}
$$

この值は，よくいわれている $\widehat{M}_{w w}$ 平均2》対応するも のである。(11)式において， $\gamma=0$ の場合は，重量平均分 子量に対応し， $\gamma=1$ の場合は，数平均分子量に対応す る。

$$
\left.\begin{array}{cc}
\gamma=0 & \bar{M}_{S D}=\frac{\sum_{i} w_{i} M_{i}}{\sum_{i} w_{i}} \equiv \bar{M}_{w} \\
\gamma=1 & \bar{M}_{S D}=\frac{\sum_{i} w_{i}}{\sum_{i} w_{i} \mid M_{i}} \equiv \bar{M}_{n}
\end{array}\right\}
$$

普通の鎖状高分子溶液では, $r$ の值は 0.5 上り大きく, $2 / 3$ より小さいので $\bar{M}_{S D}$ は必ず $\bar{M}_{v}$ と $\bar{M}_{n}$ の中間に 存在する。すなわち,

$$
\bar{M}_{n}<\bar{M}_{S D}<\bar{M}_{w}
$$

このように，重量平均分子量， $\bar{M}_{w}$, または数平均分子 量 $\bar{M}_{n}$ と比較して議論できるので，われわれは，今後， $\bar{M}_{S D}$ は, 常に $n=1$ の場合の値, つまり, 拡散定数は モーメント法によって得た值を使い，沈降定数は，普通 のとおり，沈降曲線の極大の位置加ら求めた值を使うこ とにする。また(11)式から明らかなように， $\bar{M}_{S D}$ の值 は, $\gamma$ の值によって変わる。ということは, 同一の試料 でも測定する溶媒が異なれば，珙なった分子量を值とし ては与えるといらことである。これはちょうど，粘度平 均分子量 $\bar{M}_{v}$ が，溶媒仙って異なった值を与えるのと 全く同し現象であって，分子量を測定するための沈降速 度法や粘度法が, 光散乱や浸透圧測定のような絶対法と 異なる最大の弱点であろう。

な扔, 最近, 小林柱 $\bar{M}_{S D}$ に対し, 沈降定数执よび拡 散定数ともに重㽢平均值を使った場合には、つぎのよう に示されると述べている゙。

$$
\bar{M}_{S D}=\left[\sum_{i} M_{i}^{(2-a) / 8} w_{i}\right]\left[\sum_{i} M_{i}^{-(1+a) / 8} w_{i}\right]^{-1}
$$

ここに $\alpha$ 虹粘度則

$$
[\eta]=K_{I} M^{\alpha}
$$

によって示される指数である。小林の式は，われわれの 式に拈けて,

$$
1-\gamma=\frac{(2-\alpha)}{3}
$$

*1 付緑 A を参照 
とおいたものと等しく, Flory の摩擦理論8) を使えば, (16) 式の証明は可能なので, 形式的にもわれわれの式と 同じものである。

\section{3. 考察}

今まで述べてきたように，分子量分布をもつ高分子物 質の沈降速度法によって得られた分子量 $\bar{M}_{S D}$ の平均値 の性質と, 重量平均分子量, $\bar{M}_{w}$, 数平均分子量 $\bar{M}_{n}$ との 間の大小関係は明らかとなった。ここでわれわれは, 二， 三のモデル計算を行なって，今まで明らかにしたことを さらに確かめてみようと思う。

\section{$3.1{ }_{n} M_{S D}$ の $n$ による変化}

われわれは先に，最も実験と比較しやすく， $\bar{M}_{w}, \bar{M}_{n}$ などと比較して有意なものは $n=1$ の場合であると述べ たが, (10)式において $n$ の值を变化させると, ${ }_{n} \bar{M}_{S D}$ の 值はどのように変化するかをモデル計算によって調べ た。系はポリスチレンの MEK 溶液とし, 分子量の重量 分布は 10 万から 100 万の間に矩形分布をしていると仮 定した。ポリスチレンの MEK 溶液の場合は $\gamma$ の值は 0.53 である ${ }^{9)}$ ここれによって得られた值を Table 1 に示 す。分子量 ${ }_{n} \bar{M}_{S D}$ の值は, $n$ とともに変化する。この場

Table 1 Variation of ${ }_{n} \bar{M}_{S D}$ with $n$. (104 unit)

\begin{tabular}{l|c|c|c|c}
\hline & ${ }_{1} S_{\text {mix }}$ & ${ }_{2} S_{\text {mix }}$ & ${ }_{3} S_{\text {mix }}$ & ${ }_{4} S_{\text {mix }}$ \\
\hline${ }_{1} D_{\text {mix }}$ & 45.6 & & & \\
${ }_{2} D_{\text {mix }}$ & & 43.8 & & \\
${ }_{3} D_{\text {mix }}$ & & & 42.8 & \\
${ }_{4} D_{\text {mix }}$ & & & & 42.4 \\
\hline
\end{tabular}

$\gamma=0.53, \quad \bar{M}_{w}=55 \times 10^{4}, \quad \bar{M}_{n}=39.1 \times 10^{4}:$ We assumed rectangular distribution.

合には, $n$ が大きくなれば, ある值に近づくように思わ れる。当然この変化の様子は, $\gamma$ の值抢よび分子量分布 の幅と形によって変化すると考えられる。また, 通常, 高次の沈降定数を得るためには, 沈降定数の重量分布を 測定せね䄈ならないので, $n$ が 1 以外の ${ }_{n} \bar{M}_{S D}$ を考察す ることは，それほど，意味をもったことではない。

$3.2 \bar{M}_{S D}$ の $\gamma$ による変化

次にわれわれは $\bar{M}_{S D}$ の值が $\gamma$ の変化によって, どの

Table 2 Variation of $\bar{M}_{S D}$ with $\gamma$ in various molecular weight distributions ( $10^{4}$ unit)

\begin{tabular}{l|c|c|c|c|c|c|c}
\hline \hline \multirow{2}{*}{ Distribution } & $\bar{M}_{w}$ & \multicolumn{7}{|c|}{$\gamma$} & $\bar{M}_{n}$ \\
& & 0.5 & 0.6 & 0.7 & 0.8 & 0.9 & \\
\hline rectangular & 55 & 47.2 & 45.6 & 43.9 & 42.3 & 40.7 & 39.1 \\
triangular & 40 & 34.2 & 33.1 & 32.0 & 30.9 & 29.9 & 28.9 \\
Gaussian & 50 & 49.7 & 49.1 & 49.6 & 50.1 & 49.5 & 49.5 \\
\hline
\end{tabular}

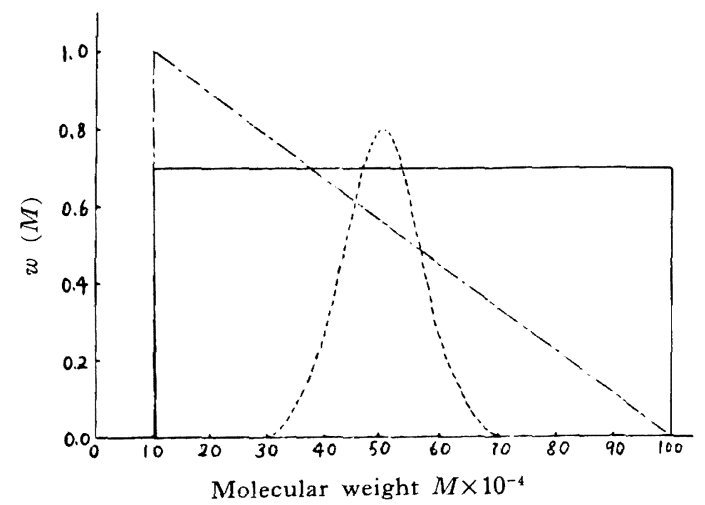

Fig. 1 Molecular weight distribution curves used for model calculation

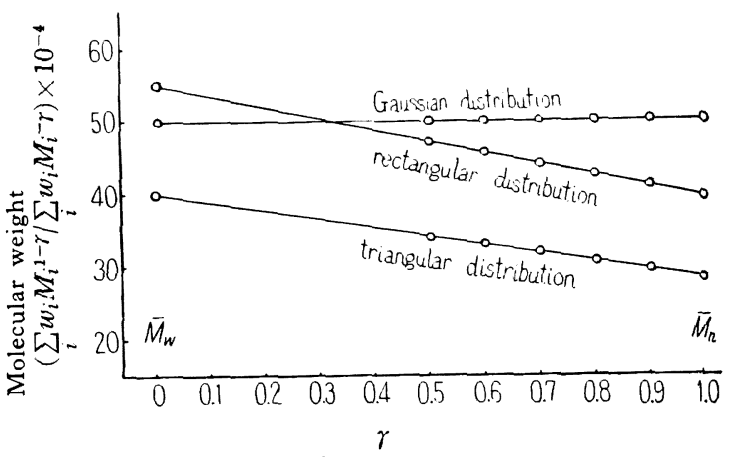

Fig. 2 Plot of $\bar{M}_{S D}$ vs. $\gamma$ (Model calculation)

よらに変わっていくかを調べてみた。すでに(13)式で示 したように， $\bar{M}_{S D}$ は $\bar{M}_{n}$ より大きく $\bar{M}_{w}$ より小さい。 しかも，(11)式でわかるようにの関数である。このこ とは，たとえ同一試料の沈降，拡散の測定を行なったと しても，溶媒が異なれば異なった分子量 $\bar{M}_{S D}$ の值を与 えるという，非常に興味ある結果を与える。そこでわれ われは, 分子量の重量分布に矩形分布, 三角形分布, お よびガウス分布を与え，(11)式によって，rおよび分布の 変化した場合の $\bar{M}_{S D}$ を計算した。計算に用いた分子量 分布曲線は Fig. 1 に示す。得られた結果は Table 2 と Fig. 2 に示す。この結果からいいらることは, 分子量 $\bar{M}_{S D}$ の值は, $\gamma$ とともに直線的に 変化する。そして $\bar{M}_{S D}$ と重量平 均分子量 $\bar{M}_{v}$, 数平均分子量 $\bar{M}_{n}$ との間に

$$
\bar{M}_{S D}=\bar{M}_{w}-r\left(\bar{M}_{w}-\bar{M}_{n}\right)
$$

の関係が成立していることであ る。しかもその直線の勾配，すな 
わち $\bar{M}_{w}$ と $\bar{M}_{n}$ の差は, 分布の形と, その分子量範囲に よって決定される。(17) 式の正当性は, 実験事実によっ て支持されなければ何ともいえないし，たまたまここに 用いた分布関数だけには成立したとしても，一般の分布 関数の場合，必ずしも正当であるとはいいがたい。

\section{付 録 $\mathbf{A}$}

Flory に従えば, 沈降定数 $S_{0}$ はつぎのように示され $3^{8)}$ 。

$$
S_{0}=\frac{\Phi_{3}^{2} P^{-1}(1-\bar{v} \rho) M_{3}^{2}}{N_{A} \eta_{0}[\eta]^{\frac{1}{3}}}
$$

ここに, $\Phi_{2}^{\frac{1}{2} P^{-1}}$ はすべての鎖状高分子溶液では定数で あって $2.5 \times 10^{6}$ といら值をもっている。また $N_{A}$ はア ボガドロ数, $\eta_{0}$ は溶媒の粘度, $[\eta]$ は溶液の極限粘度数, $\bar{v}$ は溶質の部分比容, $\rho$ は溶媒の比重, $M$ は高分子の分 子量である。(A-1) 式に, 粘度式(15)を代入すれば, 次 式のようになる。

$$
\begin{aligned}
S_{0} & =\left\{\frac{\Phi_{3}^{1} P^{-1}(1-\bar{v} \rho)}{N_{A^{\eta_{0}} K_{J^{3}}}}\right\} M^{\frac{(2-\alpha)}{3}} \\
& =K_{I I} M^{\frac{(2-\alpha)}{3}}
\end{aligned}
$$

しかるに(6)式により

$$
S_{0}=K_{I I} M^{1-\gamma}
$$

であるから，

$$
1-\gamma=\frac{(2-\alpha)}{3}
$$

が成立する。

$$
\text { 付 録 B }
$$

一般に分子量分布関数としてよく使われる Schulz の 分布関数で, (17)式が成立することを示す。Schulz の分 布関数はつぎのようにかける。

$$
f(M)=A M^{z} \exp (-\beta M)
$$

$$
\int_{0}^{\infty} f(M) d M=1=\frac{A}{\beta^{z+1}} \Gamma(z+1)
$$

この関数を使って, $\bar{M}_{n}, \bar{M}_{w}, \bar{M}_{S D}$ の定義式に従えばつ ぎのように書くことができる。

$$
\begin{gathered}
\bar{M}_{n}=1 / \int_{0}^{\infty} \frac{1}{M} f(M) d M=\frac{z}{\beta} \\
\bar{M}_{w}=\int_{0}^{\infty} M f(M) d M=\frac{z+1}{\beta}=\frac{z+1}{z} \bar{M}_{n} \\
\bar{M}_{S D}=\frac{\int_{0}^{\infty} M^{1-\gamma} f(M) d M}{\int_{0}^{\infty} M^{-\gamma} f(M) d M}=\frac{z-\gamma+1}{\beta}
\end{gathered}
$$

一方, (B-3), (B-4) 式を(17)式に代入すれば

$$
\begin{aligned}
\bar{M}_{S D} & =\bar{M}_{w}-\gamma\left(\bar{M}_{w w}-\bar{M}_{n}\right) \\
& =\frac{z-\gamma+1}{\beta}
\end{aligned}
$$

となり，これは，(B-5)式と等しい。ゆえに， $\bar{M}_{S D}$ が とともに直線的に変化することは，通常われわれが用い ている分布関数では正しいということができる。

付 記; 本報告は, 1960 年, 日本化学会第 13 年会に打 いて報告した。

$$
\text { 文献 }
$$

1) N. Gralén : Kolloid Z., 95, 188(1941)

2) S. Singer: J. Polymer Sci., 1, 445(1946)

3) 小林英彦: J. Polymer Sci., 39, 369 (1959)

4) 細野正夫, 桜田一郎: 高化, 10, 85 (1953)

5) N. Gralén and G. Lagermalm: J. Phys. Chem., 56, 514 (1952)

6）山田信夫：通研研究実用化報告, 8, 1257 (1959)

7) R. Simha: J. Chem. Phys., 13, $188(1945)$

8) P. J. Flory: Principles of Polymer Chemistry, 626 (1953)

9) A.F. Schick and S. J. Singer: J. Phys. Colloid Chem., 54, 1028(1950)

\section{The Studies of Molecular Weight Distribution and Properties of Dilute Solutions}

I. On the Average Molecular Weights Obtained from Sedimentation and Diffusion Constants of Polymer Solutions

By Nobuo Yamada and Hideomi Matsuda

It is shown that the average molecular weight $\bar{M}_{S D}$ obtained from sedimentation and diffusion measurement (making use of Svedverg's equation) is given by the equation 


$$
\bar{M}_{S D}=\frac{\sum_{i} w_{i} M_{i}{ }^{1-\gamma}}{\sum_{i} w_{i} M_{i}^{-r}}
$$

where, $\gamma$ is given by the relation, $D=K_{I I I} M^{-\gamma}$, between molecular weight $M$ and diffusion constant $D$. Moreover, $\bar{M}_{S D}$, is expressed in terms of weight average molecular weight, $M_{w}$, and number average molecular weight, $\bar{M}_{n}$ as follows:

$$
\bar{M}_{S D}=\bar{M}_{w}-\left(\bar{M}_{w}-\bar{M}_{n}\right) r
$$

第 2 報 沈降および拡散測定によって得られる

分子量の平均值 (実験)

(1960 年 9 月 1 日受理)

山田信夫・松田英臣

\begin{abstract}
要 旨 前報において, Svedverg の関係式から得られる分子量 $\bar{M}_{S D}$ の平均の性質を明らかにし， $\bar{M}_{w}, \bar{M}_{n}$ との相互関係を述べたので，その結論の正当性を検討するために，ポリスチレンの MEK 溶液の沈 降, 拡散, 光散乱の実験を行なった。そして沈降と拡散から分子量分布曲線を求め, 各分子量の平均值の定義 に従って分布曲線から計算した值と，分子量の実測値を比較して良い一致をみた。また，その相互の関倸も， $\bar{M}_{S D}=\bar{M}_{w}-\gamma\left(\bar{M}_{w}-\bar{M}_{n}\right)$ の式を実験的によく満足した。さらに, 沈降則, 拡散則として, ポリスチレンの MEK 溶液ではつぎの式が正しいことを示した。
\end{abstract}

$$
S_{0}=4.09 \times 10^{-15} M^{0.47}, \quad D_{0}=3.43 \times 10^{-4} M^{-0.53}
$$

\section{1. 緒言}

前報においてわれわれは沈降速度法によって得られ る高分子物質の分子量の平均の性質を議論してきた。す なわち，通常の方法で得られる沋降定数 $S_{0}$ ，および，モ ーメント法で得られる拡散定数 $D_{m}$ を使えば, Svedverg の関係式加求まる分子量 $\bar{M}_{S D}$ はつぎのよ5に示され ることがわかった。

$$
\bar{M}_{S D}=\frac{\sum_{i} w_{i} M_{i}^{1-\gamma}}{\sum_{i} w_{i} M_{i}^{-\gamma}}
$$

ここに, $w_{i}$ は分子量 $M_{\imath}$ なる試料の重さであり, $\gamma$ は沈 降則, 拡散則として次式に示される指数である。

$$
\begin{aligned}
S_{i} & =K_{I I} M_{i}{ }^{1-\gamma} \\
D_{i} & =K_{I I I} M_{i}{ }^{-\gamma}
\end{aligned}
$$

しかも， $\bar{M}_{S D}$ は重量平均分子量 $\bar{M}_{w}$ より小さく, 数平 均分子量 $\bar{M}_{n}$ より大きく，二，三のモデル計算の結果で は, その間に

$$
\bar{M}_{S D}=\bar{M}_{w}-\gamma\left(\bar{M}_{w}-\bar{M}_{n}\right)
$$

の関係があるように思われた。

そこでこの論文に扔いては，以上の結論が実験によっ て支持されるかどらかを検討するために，2種類の未分 別ポリスチレンの試料について, 沈降, 拡散の実験を行 なって $\bar{M}_{S D}$ を求め, さらに, 沈降法, 拡散法によってそ の試料の分子量分布を求め, その分布から (1) 式に従っ
て $\bar{M}_{S D}$ を計算して実測した $\bar{M}_{S D}$ の值と比較した。な お，われわれの得た分子量分布が正しかったかどうかの 検討のために，光散乱の測定を同時に行なって，重量平 均分子量, $\bar{M}_{w}$ の值を比較した。そして, これらの值が どの程度に (3) 式を満足するものであるかどうかという ことをも考察した。付言すれば，実測した $\bar{M}_{S D}$ と，分 布から求めた $\bar{M}_{S D}$ と一致すれば，それは分子量分布の 正しかったかどうかのめやすにもなる。

\section{2. 実験}

\section{1 試 料}

試料は未分別ポリスチレンであって，その中の一つは 光散乱の練習用試料1) として配布されたものであり，他 のものは市販のポリスチレン (M-2) である。試料は一 度, MEK に溶かしメタノールで再沈殿させて乾燥後使 用した。

\section{2 溶 媒}

溶媒としては MEK を使用した。この MEK は, 1 級 試薬を無水硫酸ソーダで乾燥した後, 2 回 蒸留したもの をアンプル中に保存しておいたものを使用した。

\section{3 沈降実験}

使用した超遠心機は，日立製作所製の電動駆動型の超 遠心機であって，測定に用いた回転数はすべて 47300 rpm である。測定時における温度は, この装置では測定 できないため, 回転の前後でローター温度を $\pm 0.1^{\circ} \mathrm{C} の$ 精度で熱電対により測定し，その平均で測定時の溶液温 度とした。沈降図形は, シュリーレン円筒レンズ法によ 